\title{
Improvements in Research Orientation and Reductions in Barriers to Research Utilization among Undergraduate Students in Health Sciences
}

Andrew A. Peachey

James Madison University, peacheaa@jmu.edu

Stephanie Baller

James Madison University, ballersl@jmu.edu

Carolyn Schubert

James Madison University, schubecf@jmu.edu

Follow this and additional works at: https://nsuworks.nova.edu/ijahsp

Part of the Medicine and Health Sciences Commons

\section{Recommended Citation}

Peachey AA, Baller S, Schubert C. Improvements in Research Orientation and Reductions in Barriers to Research Utilization among Undergraduate Students in Health Sciences. The Internet Journal of Allied Health Sciences and Practice. 2018 Jan 01;16(2), Article 7.

This Manuscript is brought to you for free and open access by the College of Health Care Sciences at NSUWorks. It has been accepted for inclusion in Internet Journal of Allied Health Sciences and Practice by an authorized editor of NSUWorks. For more information, please contact nsuworks@nova.edu. 


\title{
Improvements in Research Orientation and Reductions in Barriers to Research Utilization among Undergraduate Students in Health Sciences
}

\begin{abstract}
Purpose: Developing research skills while improving research orientation among undergraduate students may increase evidence-based practice later in their professional careers.

Method: Undergraduate Health Science students $(n=241)$ participated in a pretest-posttest design to determine the impact of a course that includes team-based, student initiated research projects completed within one semester. Modified versions of the Edmonton Research Orientation Survey (EROS) and the Barriers to Research Utilization Scale (BARRIERS) were completed at the beginning and end of the semesters.

Results: Students reported gains in six research skills and improvements in two of the Edmonton Research Orientation Survey subscales: involvement in research and evidence-based practice. Students reported reductions in all four Barriers to Research Utilization Scale subscales: adopter, organization, innovation, and communication.

Conclusion: Improvements in research orientation and reductions in perceived barriers due to high-impact learning activities may eventually facilitate evidence-based practice.

\section{Author Bio(s)}

Andrew A. Peachey, DrPH, is an Associate Professor and Acting Academic Unit Head in the Department of Health Sciences in the College of Health and Behavioral Studies at James Madison University.

Stephanie L. Baller, PhD, is an Associate Professor in the Department of Health Sciences in the College of Health and Behavioral Studies at James Madison University.

Carolyn F. Schubert, MLIS, is the Interim Director of Research \& Education Services and the Health Sciences \& Nursing Librarian at James Madison University.
\end{abstract}




\title{
IJAHSP \\ The Internet Joưnal of Allied Health Sciences and Practice
}

Dedicated to allied health professional practice and education

Vol. 16 No. 2 ISSN 1540-580X

\section{Improvements in Research Orientation and Reductions in Barriers to Research Utilization among Undergraduate Students in Health Sciences}

\author{
Andrew A. Peachey, DrPH \\ Stephanie Baller, PhD \\ Carolyn Schubert, MLIS \\ James Madison University \\ United States
}

\begin{abstract}
Purpose: Developing research skills while improving research orientation among undergraduate students may increase evidencebased practice later in their professional careers. Method: Undergraduate health science students $(n=241)$ participated in a pretest-posttest design to determine the impact of a course that includes team-based, student initiated research projects completed within one semester. Modified versions of the Edmonton Research Orientation Survey (EROS) and the Barriers to Research Utilization Scale (BARRIERS) were completed at the beginning and end of the semesters. Results: Students reported gains in six research skills and improvements in two of the EROS subscales: involvement in research and evidence-based practice. Students reported reductions in all four BARRIERS subscales: adopter, organization, innovation, and communication. Conclusion: Improvements in research orientation and reductions in perceived barriers due to learning activities may eventually facilitate evidence-based practice.
\end{abstract}

\section{INTRODUCTION}

Evidence-based practice (also known as evidence-based medicine) is the modern foundation of clinical practice and an essential component to the education of health professionals. Evidence-based practice (EBP) requires "integrating individual clinical expertise with the best available external clinical evidence from systematic research" as well as patient values and patient data. ${ }^{1}$ The process identified for EBP involves 5 key phases or steps: ask, acquire, appraise, apply, and analyze. EBP is the ability to translate ambiguity into an answerable question, basic information literacy or the ability to retrieve the highest quality evidence available, being a critical reader of the relevance and application of evidence, using the evidence in practice, and the ability to evaluate that performance. ${ }^{2}$ As Dawes et al observed, these 5 steps provide a platform not only clinical practice but also the teaching of clinical EBP. ${ }^{2}$ Melynk et al included similar steps in their 7 steps of EBP, adding an initial development of EBP culture and culminating with sharing the outcomes of the inquiry. ${ }^{3}$

Health care professionals must be able to gain, assess, apply, and integrate new knowledge and have the ability to adapt to changing circumstances throughout their professional lives. Curricula to deliver these aptitudes need to be grounded in the fivestep model of EBP and informed by ongoing research. ${ }^{2}$ In order to fulfil these steps, students often learn about effective information searching and evaluation, statistics and research methodologies and how to apply evidence back to a clinical scenario. ${ }^{4}$ Some fields have also developed more detailed competencies that demonstrate performance at each phase.3,5-6 Others have used the phases to delineate EBP and research utilization within training for individual patient care versus policy or procedure development. ${ }^{7}$

The aim of EBP is to be a flexible framework for all health professionals. The Institute of Medicine established that EBP should be a common approach shared among the many different health professions. ${ }^{8}$ Many accrediting bodies now reflect EBP and the translation of research into practice as key educational standards for health curricula. ${ }^{9-15}$ Therefore, different programs expect some form of EBP education to occur, even for those programs that have the bachelor's-level terminal degrees. Some fields, such as dietetics, occupational therapy, and public health, are also raising the expectations for students to conduct research, apply statistical analyses, and work with data collection and datasets. ${ }^{15-18}$ The growth in this area relates to the greater availability of

(c) The Internet Journal of Allied Health Sciences and Practice, 2018 
quantitative information beyond the published literature, allowing for new investigations and analyses of secondary datasets and a broader emphasis on quantitative reasoning across education as a whole. ${ }^{19}$

Despite the clear and consistent emphasis, barriers to research utilization in the clinical setting, implementation, and EBP remain a consistent challenge in practice. Common obstacles over the last few decades include the lack of knowledge, skills, and attitudes of individual health professionals and the variable EBP culture of the organizational setting..$^{20,21}$ In a systematic review of systematic reviews on this issue, Lau et al found that lack of leadership, disparate levels of skills, and poor coordination were specific barriers at the organizational level. At the individual level, health professionals noted lack of time, motivation, and lack of training or competence interfered with EBP implementation. ${ }^{21}$ Kajermo et al found these broad categories to be persistent issues over 18 years of research, despite variations in geographic settings and study sites. ${ }^{22}$

These inherited issues in practice have stemmed from the uncertainty of effective instructional practices for EBP. In many studies of EBP instructional practices, only a narrative description of the instruction and no assessment was provided. ${ }^{4}$ For studies in which learning was assessed, the majority of the emphasis was on the first three phases: ask, acquire, and appraise. In short, the focus of existing coursework about EBP is on developing a literature review. Therefore, the other remaining phases, apply and analyze, were often left out of the educational process, excluding opportunities to develop quantitative reasoning and critical thinking skills when using raw data. For students, they perceive this separation as a disconnect between educational experiences and actual clinical practice. ${ }^{23}$ Assessments also tend to lack "rigorous quantitative methods" and consistency in reporting. ${ }^{4,24}$

To engage in research and contribute to the evidence base of their fields, health professionals must not only possess the prerequisite skills to conduct research but also possess the desire to do so and the ability to overcome barriers to research utilization in professional settings. The Edmonton Research Orientation Survey (EROS) has been used in numerous allied health professions, including nurses, rehabilitation therapists, occupational therapists, physical therapists, and speech-language pathologists. ${ }^{25-30}$ Henderson et al used the EROS to measure the impact of an educational intervention among nurses. ${ }^{31}$ The Barriers to Research Utilization scale (BARRIERS) has been used in many cross-sectional studies to assess challenges among nurses and less frequently within interventions to measure change.22,32

In order to improve EBP instructional practices, instructors must then also ground the work in sound pedagogical practices and motivate students to engage in EBP. Thomas et al recommended a general framework for instructors to teach EBP:

1. Consider the learner's existing knowledge, beliefs, and attitudes regarding EBP.

2. Understand the salient role of social negotiation and collaboration with peers in incorporating evidence in clinical decision making.

3. Acknowledge that the learning situations, content, and learning activities are meant to foster self-analysis, problem solving, higher-order thinking, and deep understanding; therefore, they must be relevant, authentic, and represent the natural complexities of the world.

4. Support collaborative learning that exposes students to alternative viewpoints and affords them the opportunity of apprenticeship learning.

5. Scaffold learners from knowledge that is presently known to that which is to be known, thereby facilitating the learner's ability to perform just beyond the limits of current ability. ${ }^{33(p .265)}$

Undergraduate research serves an important aspect of high-impact learning. ${ }^{34}$ Many of the items in the framework and educational techniques presented by Thomas et al are activities identified by the National Survey of Student Engagement (NSSE) as student engagement indicators and high-impact educational practices. ${ }^{33,35}$ Higher order learning, reflective and integrative learning, and collaborative learning are three of the most significant engagement indicators for students. ${ }^{36}$ Thomas et al recommend "collaborative learning methods, case-based methods, and cognitive apprenticeships" as effective techniques to teach EBP, similar to the high-impact practices of research with faculty. 33,35 However, only $19 \%$ of undergraduate health professions students complete a research experience with a faculty member. ${ }^{36}$ By not completing a research design course or participating in research, clinicians may be less likely to incorporate research findings into practice. ${ }^{37}$

In this manuscript, the effect of a health research methods course on undergraduate pre-professional health student preparation, particularly around students' perceptions of research utilization and evidence-based practice was explored. In particular, the course involved students collaboratively working in teams to complete an original research study within one semester.

(C) The Internet Journal of Allied Health Sciences and Practice, 2018 


\section{METHODS}

Undergraduate students enrolled in a senior level, health research methods course required within a health sciences curriculum at a mid-sized, mid-Atlantic university were recruited to participate in this one group, pretest-posttest pre-experimental study to improve research orientation and reduce barriers to research. The study was approved by the Institutional Review Board (IRB) of the university prior to data collection. Informed consent was obtained from all individual participants included in the study.

\section{Participants}

Of the 301 students who agreed to participate in the research, 60 were excluded in the analyses due to incomplete data: 41 completed only the pretest, 7 completed only the posttest, and 12 had incomplete data on either the pretest or posttest. Scores of those excluded from the analyses were compared with the 241 participants included in the analyses. No significant differences were found.

Descriptive statistics of the participants are presented in Table 1. The majority of participants were female students (83.8\%) and 21 years old or older at the beginning of the semester. Becoming an occupational therapist was the most common career goal (24.1\%), followed by nurse/nurse practitioner (14.9\%) and physician assistant (14.9\%).

Table 1. Baseline Characteristics of Participants

\begin{tabular}{|c|c|c|}
\hline Demographics & $N$ & $\%$ \\
\hline \multicolumn{3}{|l|}{ Sex } \\
\hline Male & 39 & 16.2 \\
\hline Female & 202 & 83.8 \\
\hline \multicolumn{3}{|l|}{ Age (years): } \\
\hline 19 & 1 & 0.4 \\
\hline 20 & 21 & 8.7 \\
\hline 21 & 154 & 63.9 \\
\hline 22 & 55 & 22.8 \\
\hline $23+$ & 10 & 4.1 \\
\hline \multicolumn{3}{|l|}{ Career Goals } \\
\hline Nurse/Nurse Practitioner & 36 & 14.9 \\
\hline Occupational Therapist & 58 & 24.1 \\
\hline Physical therapist & 28 & 11.6 \\
\hline Physician assistant & 36 & 14.9 \\
\hline Public health & 23 & 9.5 \\
\hline Other health related & 43 & 17.8 \\
\hline Non-health related & 2 & 0.8 \\
\hline \multirow[t]{2}{*}{ Unsure } & 15 & 6.2 \\
\hline & $M$ & $S D+$ \\
\hline GPA & 3.03 & 0.40 \\
\hline
\end{tabular}

\section{Procedure}

Within a one group, pretest-posttest, pre-experimental study, data were collected from students in any of the 4 semesters from August 2014 to May 2016. Following the informed consent procedure, data were collected using an online instrument twice during the semester. During the first 2 weeks of the course, students completed an online instrument to assess research orientation and perceived barriers to utilization of research in practice. During the semester, students completed a student-initiated, IRB approved research project. The project included the development of a research question and hypotheses based upon a literature review, followed by the development of a research proposal submitted for IRB approval. Following IRB approval, students collected and analyzed the data and reported their findings in an oral presentation and written report. A detailed description of the course is reported elsewhere. ${ }^{38}$ During the final 2 weeks of the course, students repeated the online instrument. 


\section{Measures}

Edmonton Research Orientation Survey. The EROS is divided into 3 sections. ${ }^{37}$ After demographic questions and questions of research experience, participants were instructed to report their level of understanding $(1=$ very poor to $5=$ very good) in the follow areas: research design, statistics, research articles in journals, grant application procedures, and ethical review procedures. The second section included 38 items divided among 4 constructs: valuing research, research involvement, being at the leading edge, and evidence-based practice. For this study, each item was rated from 1 being strongly disagree to 4 being strongly agree. The final section included 5 items to assess the support and barriers toward applied research. Higher scores represented stronger research orientation. The internal consistency of the total EROS score in this study is similar to the high internal consistency reported by Pain et $a l, \alpha=.92$ and $\alpha=.93$, respectively. Within the current study, the internal consistency of the sub-scores were valuing research $(\alpha=.74)$, involvement $(\alpha=.81)$, being at the leading edge $(\alpha=.73)$, and evidence-based practice $(\alpha=.79) .37$

Barriers to Research Utilization Scale. The BARRIERS instrument was developed within the lens of the diffusion of innovation theory to measure barriers to research utilization among nurses. ${ }^{20}$ To make the survey applicable to a wider array of future health professionals, the term "nurse" was replaced with "I." The 29 items were divided among 4 subscales: characteristics of the adopter, characteristics of the organization, characteristics of the innovation, and characteristics of the communication. For this study, each item was rated from 1 being strongly disagree to 4 being strongly agree. Higher scores represented greater perceived barriers to research utilization. The internal consistency of the total BARRIERS score in this study was $\alpha=.93$. Within the current study, the internal consistency of the subscales was equal to or exceeded those reported by Funk et al: characteristics of the adopter $(\alpha=.80, a=.80)$, characteristics of the organization $(\alpha=.86, \alpha=.80)$, characteristics of the innovation $(a=.75, a$ $=.72$ ), and characteristics of the communication ( $\alpha=.75, \alpha=65$ ). Funk et al report test-retest reliabilities as measured by Pearson correlations between 0.68 and 0.83 and factor loadings above 0.40 for all items. ${ }^{20}$

Statistical Analysis. Pretest scores were compared with posttest scores of the EROS items that assessed knowledge and skills of using and conducting research by Wilcoxon sign rank tests. Pretest scores were compared with posttest scores of the EROS and BARRIERS scales by paired sample t tests. Analyses were conducted in IBM SPSS Statistics for Windows version 24. ${ }^{39}$

\section{RESULTS}

Table 2. Pretest-posttest Comparison of Understanding of Research Skills Using Wilcoxon Matched Pairs Sign Rank Tests

Pretest Postest

\begin{tabular}{|c|c|c|c|c|c|c|}
\hline Variable & $M$ & $\mathrm{SD} \pm$ & $M$ & $\mathrm{SD} \pm$ & z & $p$ \\
\hline \multicolumn{7}{|l|}{ EROSA } \\
\hline Using databases to search for literatureb & 3.95 & 0.77 & 4.49 & 0.63 & -8.33 & $<.001$ \\
\hline Research design & 3.09 & 0.82 & 4.03 & 0.72 & -10.71 & $<.001$ \\
\hline Statistics & 3.22 & 0.85 & 3.72 & 0.87 & -7.62 & $<.001$ \\
\hline Reading and understanding scientific articles & 3.76 & 0.79 & 4.18 & 0.67 & -7.06 & $<.001$ \\
\hline Research proposals/grant application procedures ${ }^{c}$ & 2.55 & 0.89 & 3.75 & 0.92 & -11.13 & $<.001$ \\
\hline Ethical review procedures & 2.97 & 0.91 & 4.03 & 0.84 & -11.03 & $<.001$ \\
\hline
\end{tabular}

Edmonton Research Orientation Survey

a $1=$ very poor to $5=$ very good

$\mathrm{b}$ added question not in original EROS

$\mathrm{c}$ modified from EROS

Wilcoxon matched pairs sign rank tests were conducted to compare pretest knowledge and skills with posttest (Table 2). Participants reported significant gains in all six areas: using databases to search for literature, research design, statistics, reading \& understanding scientific articles, research proposals/grant application procedures, and ethical review procedures.

Paired-samples $t$ tests were conducted to compare pretest EROS and BARRIERS subscales with posttest (Table 3). Among the four EROS subscales, both involvement and evidence scores significantly improved from pretest to posttest while the increase in valuing and edge from pretest to posttest was not significant. There was a significant difference in the Involvement score at pretest $(M=4.41, S D \pm 0.49)$ and Involvement score at posttest $(M=2.62, S D \pm 0.50), t(240)=-6.488, p<.001$. There was a significant difference in the Evidence-based practice score at pretest $\left(M=2.84, S_{ \pm} \pm 0.35\right)$ and Evidence-based practice score at posttest $(M$ $\left.=2.94, S D_{ \pm} 0.37\right), t(240)=-3.968, p<.001$. There was not a significant difference in valuing scores at pretest $\left(M=3.06, S D_{ \pm}\right.$ 
$0.36)$ and valuing scores at posttest $(M=3.08, S D \pm 0.38), t(240)=-.760, p=.448$. There was not a significant difference in leading edge scores at pretest $(M=3.02, S D \pm 0.41)$ and leading edge scores at posttest $(M=3.04, S D \pm 0.43), t(240)=-.886, p=.377$.

Table 3. Pretest-Posttest Comparison of Research Orientation and Barriers to Research Utilization Using Paired Sample t Tests

\begin{tabular}{|c|c|c|c|c|c|c|c|c|}
\hline & \multicolumn{2}{|c|}{ Pretest } & \multicolumn{2}{|c|}{ Posttest } & & & \multicolumn{2}{|c|}{$95 \% \mathrm{Cl}$} \\
\hline Variable & $M$ & $S D+$ & $M$ & $S D+$ & $T(240)$ & $P$ & $L L$ & $U L$ \\
\hline \multicolumn{9}{|l|}{ EROS } \\
\hline Valuing & 3.06 & 0.36 & 3.08 & 0.38 & -0.760 & .448 & -0.07 & 0.03 \\
\hline Involvement & 2.41 & 0.49 & 2.62 & 0.50 & -6.488 & $<.001$ & -0.27 & -0.15 \\
\hline Leading Edge & 3.02 & 0.41 & 3.04 & 0.43 & -0.886 & .377 & -0.08 & 0.03 \\
\hline Evidence-based Practice & 2.84 & 0.35 & 2.94 & 0.37 & -3.968 & $<.001$ & -0.15 & -0.05 \\
\hline \multicolumn{9}{|l|}{ BARRIERS } \\
\hline Adopter/self & 2.17 & 0.41 & 2.05 & 0.44 & 4.038 & $<.001$ & 0.07 & 0.19 \\
\hline Organization/setting & 2.44 & 0.46 & 2.31 & 0.52 & 3.994 & $<.001$ & 0.07 & 0.19 \\
\hline Innovation/research & 2.39 & 0.40 & 2.29 & 0.48 & 3.610 & $<.001$ & 0.05 & 0.17 \\
\hline Communication/presentation & 2.33 & 0.41 & 2.17 & 0.46 & 5.384 & $<.001$ & 0.10 & 0.22 \\
\hline
\end{tabular}

EROS = Edmonton Research Orientation Survey

BARRIERS $=$ The Barriers to Research Utilization Scale

1 = strongly disagree to 4 = strongly agree

All four BARRIERS subscales (adopter, organization, innovation, and communication barriers) significantly improved from pretest to posttest. There was a significant difference in the adopter scores at pretest $(M=2.17, S D+0.41)$ and adopter scores at posttest $(M=2.05, S D+0.44), t(240)=4.038, p<.001$. There was a significant difference in the organization scores at pretest $(M=2.44$, $\mathrm{SD}+0.46)$ and Organization scores at posttest $(M=2.31, \mathrm{SD}+0.52), \mathrm{t}(240)=3.994, \mathrm{p}<.001$. There was a significant difference in the innovation scores at pretest $(M=2.39, S D+0.40)$ and innovation scores at posttest $(M=2.29, S D+0.48), t(240)=3.610, p$ $<.001$. There was a significant difference in the communication scores at pretest $(\mathrm{M}=2.33, \mathrm{SD}+0.41)$ and communication scores at posttest $(M=2.17, S D+0.46), t(240)=5.384, p<.001$.

\section{DISCUSSION}

The course showed improvement in understanding and skills of the participants. Through the inclusion of the student-initiated, IRBapproved research project, participants reported gains in their understanding of using databases to search for literature, research design, statistics, reading and understanding scientific articles, research proposals/grant application procedures, and ethical review procedures. Within the course, students were required to search multiple databases to identify, critique, and utilize the evidence from journal articles as part of the development of a literature review to support the research proposal. Students must successfully complete ethical training for research with human subjects prior to submitting their own project for IRB review. Students developed multiple hypotheses, aggregated instrumentation to measure assessed variables, and then selected, conducted, and reported appropriate statistical tests for the results section of the presentation and paper. Bonner and Sando reported that nurses who completed a university research course had greater understanding of the components necessary to conduct research. ${ }^{28} \mathrm{It}$ may be possible to develop and understanding of these skills without the inclusion of the research project.

Both at pretest and posttest, the order of research orientation scores remained consistent: valuing research (highest), being on the leading edge, evidence-based practice, and involvement in research (lowest). At the beginning of the study, participants already valued research and believed research was important for being on the leading edge. Previous courses and professional expectations may have increased these beliefs prior to enrollment in the research course. There was less room for improvement within these two scores. Among professionals, valuing research and being at the leading edge tended to be higher than research involvement and evidence-based practice. Pairwise comparisons indicated that participants had similar ratings for valuing research and for leading edge research at the conclusion of the course and that these ratings were higher than research involvement and evidence-based practice. Prior to an intervention among nurses in Australia, being on the leading edge and valuing research were the highest research orientation scores. ${ }^{31}$ Similar patterns were found among occupational therapists. ${ }^{25-27}$

The course did increase scores, reflecting projected involvement in research and use of evidence-based practice in their intended careers. Among the participants, the lowest research orientation score occurred for involvement in research both initially and at follow-up. This finding is consistent with research orientation among practicing health professionals, including occupational therapists in South Africa, pediatric occupational therapists in Australia, and nurses in Australia. ${ }^{25-27,31}$ Although involvement in

(C) The Internet Journal of Allied Health Sciences and Practice, 2018 
research remained the lowest research orientation score at posttest, the participants reported the greatest gain. In their intervention designed to increase research orientation among nurses, Henderson et al also report a gain in involvement in research, although the finding was not statistically significant. ${ }^{31}$

Both at pretest and posttest, the order of barriers to research utilization remained consistent: characteristics of adopter (lowest), communication, innovation, and organization (highest). The course reduced all of the categories of barriers to research utilization. In the development of the instrument among nurses, characteristics of the research/innovation was lowest followed by communication/presentation, adopter/nurse, and organization/setting..$^{20}$ In a review of over 60 studies since the instrument was developed, Kajermo et al identified characteristics of the setting/organization and the presentation of the research findings were perceived as the greatest barriers to research utilization. ${ }^{22}$ In their integrative review of 45 studies, Carlson and Plonczynski also report characteristics of the organization are the most common barrier reported. ${ }^{32}$

Among undergraduate seniors, less than one-quarter (24\%) reported conducting research with a faculty member and less than one-half $(45 \%)$ reported a culminating senior experience. ${ }^{36}$ Among students who identified as having a health profession major, engagement in these high-impact practices is even lower: $19 \%$ and $38 \%$, respectively. The student-initiated research project embedded within a course in research methods was used as an opportunity to increase engagement in an undergraduate curriculum while contributing to developing a foundation for evidence-based practice further developed in graduate programs.

Consistent with the first phases of developing skills for evidence-based practice in health professions, the students developed skills essential to critical thinking and setting the foundation for continuing education in professional programs. ${ }^{2,33}$ The students developed the ability to refine and translate ambiguous suppositions into questions that were answerable and to propose questions not yet answered in the existing literature. They greatly expanded their ability to not only locate but also apply higher quality information. Students also became much more keenly critical readers of information. Within the context of research, these students may be better able to assess the effectiveness of their clinical interventions within clinical populations rather than only among individual patients, thereby contributing to the evidence base. These improvements in skill and knowledge represented the first three phases set out by Dawes et al and that are essential foundation pieces for subsequent professional programs in which they should receive the final two steps of using evidence in practice and the ability to evaluate that performance. ${ }^{2}$

\section{Limitations}

Possible limitations of the study may result from the one group, pretest-posttest, pre-experimental study design. While able to assess changes in research orientation through the administration of the instruments at the beginning and end of the semester, the design has inherent threats to internal validity. Within this study, the threat of testing situation was reduced by separating the pretest and posttest by approximately 3 months. The threat of history was reduced by including students across multiple semesters. Furthermore, there was no sequencing of courses within the curriculum that would be expected to change research orientation during the time students were enrolled in the research methods course.

Including participants from one undergraduate program within one university may limit the generalizability of the findings. However, the participants reported a variety of intended health professions that value evidence-based practice. The university focused on undergraduate education and facilitated timely reviews of exempt research. Additionally, participants self-reported understanding of research skills rather than using course products or other object measures. Because the students have not experienced the demands of professional practice, the intentions to conduct research and the perceptions of barriers maybe altered by subsequent educational experiences and clinical experiences. However, changing confidence and intention early in professional preparation may be more effective than trying to change orientation once in practice.

\section{CONCLUSION}

Participants improved the two lowest aspects of their research orientation (involvement in research and evidence-based practice) and reduced all four barriers to research utilization. Improvements in these aspects of research orientation is particularly significant because they are also typically lowest among health professionals.

\section{REFERENCES}

1. Sackett DL, Rosenberg WMC, Gray JAM, Haynes RB, Richardson WS. Evidence based medicine: What it is and what it isn't. BMJ. 1996;312:71-2. [PMID: 8555924] http://dx.doi.org/10.1136/bmj.312.7023.71

2. Dawes M, Summerskill W, Glasziou P, Cartabellotta A, Martin J, et al. Sicily statement on evidence-based practice. BMC Med Educ. 2005;5:1-7. [PMID: 15634359] doi: 10.1186/1472- 6920-5-1

3. Melynk BM, Gallagher-Ford L, Long LE. The establishment of evidence-based practice competencies for practicing registered nurses and advanced practice nurses in real-world clinical settings: proficiencies to improve healthcare

(c) The Internet Journal of Allied Health Sciences and Practice, 2018 
quality, reliability, patient outcomes, and costs. Worldviews Evid Based Nurs. 2014;11(1):5-15. [PMID: 24447399] doi: 10.1111/wvn.12021

4. Hitch D, Nicola-Richmond K. Instructional practices for evidence-based practice with pre- registration allied health students: A review of recent research and developments. Adv Health Sci Educ Theory Pract. 2016;1-15. [PMID: 27469244] doi:10.1007/s10459-016-9702-9

5. Asokan G. Evidence based practice curriculum in allied health professions for teaching-research- practice nexus. J Evid Based Med. 2012;5(4):226-31. [PMID: 23557503] doi:10.1111/jebm.12000

6. Council for Training in Evidence-Based Behavioral Practice. Definition and competencies for Evidence-Based Behavioral Practice (EBBP); 2008. Available at: http://www.ebbp.org/documents/EBBP_Competencies.pdf. Accessed: December 18, 2017.

7. de Groot M, van der Wouden, JM, van Hell EA, Nieweg MB. Evidence-based practice for individuals or groups: let's make a difference. Perspect Med Educ. 2013;2:216-21. [PMID: 24101580] doi: 10.1007/s40037-013-0071-2

8. Institute of Medicine. The core competencies needed for health care professionals. In: Briere R, ed. Health Professions Education: A Bridge to Quality. Washington DC: National Academies Press; 2003. https://www.ncbi.nlm.nih.gov/books/NBK221519/.

9. American Association of Colleges of Nursing. The Essentials of Baccalaureate Education for Professional Nursing Practice; 2008. Available at: http://www.aacnnursing.org/Portals/42/Publications/BaccEssentials08.pdf. Accessed: December 18, 2017.

10. Accreditation Council for Education in Nutrition and Dietetics. ACEND Accreditation Standards for Nutrition and Dietetics Didactic Programs (DPD). Effective June 1, 2017. Available at: http://www.eatrightpro.org/ /media/eatrightpro\%20files/acend/about\%20program\%20accreditatio n/accreditation\%20standards/2017standardsfordpdprograms.ashx Accessed: December 18, 2017.

11. Accreditation Review Commission on Education for the Physician Assistant. Accreditation Manual, 4th ed; 2016. Available at: http://www.arc-pa.org/wp- content/uploads/2016/10/AccredManual-4th-edition-May-2016-FNL.pdf. Accessed: December 18, 2017.

12. Commission on Accreditation of Athletic Training Education. Standards for the Accreditation of Professional Athletic Training Programs; 2015. Available at: http://caate.net/wp- content/uploads/2015/12/2012-Professional-Standards.pdf. Accessed: December 18, 2017.

13. Commission on Accreditation in Physical Therapy Education. Standards and Required Elements for Accreditation of Physical Therapist Education Programs. Available at: http://www.capteonline.org/uploadedFiles/CAPTEorg/Portal/CAPTEPortal_PTStandardsEvidence.doc Accessed: December 18, 2017.

14. Liaison Committee on Medical Education. Functions and Structure of a Medical School - (contains the LCME Standards); 2016. Available at: http://lcme.org/wp- content/uploads/filebase/standards/2017-18_Functions-andStructure_2016-09-20.docx. Accessed: December 18, 2017.

15. Accreditation Council for Occupational Therapy Education. 2011 Accreditation Council for Occupational Therapy Education (ACOTE囚) Standards and Interpretive Guide - April 2017 Interpretive Guide Version. Available at: http://www.aota.org/ /media/Corporate/Files/EducationCareers/Accredit/Standards/2011- Standards-and-InterpretiveGuide.pdf. Accessed: December 18, 2017.

16. Accreditation Council for Education in Nutrition and Dietetics. (2017, June). Future Education Model Accreditation Standards for Bachelor Degree Programs in Nutrition and Dietetics. Available at:

http://www.eatrightpro.org/ /media/eatrightpro\%20files/acend/futureeducationmodel/fembachelorf inal.ashx. Accessed December 20, 2017.

17. Council on Education for Public Health. Accreditation Criteria. Schools of Public Health and Public Health Programs; 2016. Available at: http://ceph.org/assets/2016.Criteria.pdf. Accessed: December 18, 2017.

18. National Physical Activity Society. Core Competencies and Knowledge, Skills, and Abilities: Essentials for Public Health Physical Activity Practitioners. Available at: http://certification.acsm.org/files/file/CoreCompetenciesPAPHS.pdf. Accessed: December 18, 2017.

19. Elrod S. Quantitative reasoning: the next "Across the Curriculum" movement. Peer Rev. 2014;16(3). https://www.aacu.org/peerreview/2014/summer/elrod

20. Funk SG, Champagne MT, Wiese RA, Tornquist EM. BARRIERS: The barriers to research utilization scale. Appl Nurs Res. 1991;4:39-45. [PMID: 1741634]doi: http://dx.doi.org/10.1016/S0897-1897(05)80052-7

(c) The Internet Journal of Allied Health Sciences and Practice, 2018 
21. Lau R, Stevenson F, Ong BN, Dziedzic K, Treweek S, et al. Achieving change in primary care - causes of the evidence to practice gap: Systematic reviews of reviews. Implement Sci. 2015;11:1- 39. [PMID: 27001107] doi: 10.1186/s13012-016-0396-4

22. Kajermo KN, Boström AM, Thompson DS, Hutchinson AM, Estabrooks CA, Wallin L. The BARRIERS scale-the barriers to research utilization scale: A systematic review. Implement Sci. 2012;5(32):1-22. [PMID: 20420696] doi: 10.1186/1748-5908-5-32

23. Benner PE, Sutphen M, Leonard V, Day L. Educating nurses: A call for radical transformation. San Francisco: JosseyBass; 2010.

24. Phillips AC, Lewis LK, McEvoy MP, Galipeau J, Glasziou P, et al. Development and validation of the guideline for reporting evidence-based practice educational interventions and teaching (GREET). BMC Med Educ. 2016;16(237). [PMID: 27599967] doi: 10.1186/s12909-016-0759-1

25. Brown T, Tseng M, Casey J, McDonald R, Lyons C. Predictors of research utilization among pediatric occupational therapists. OTJR (Thorofare N J). 2010;30(4):172-83. doi:10.3928/15394492-20091022-01

26. Lyons C, Brown T, Tseng MH, Casey J, McDonald R. Evidence-based practice and research utilisation: Perceived research knowledge, attitudes, practices and barriers among Australian paediatric occupational therapists. Aust Occup Ther J. 2011;58(3):178-86. [PMID: 21599683] doi:10.1111/j.1440-1630.2010.00900.x

27. Pitout H. Research orientation of South African occupational therapists. South African J Occup Ther. 2013;43(2):5-11.

28. Bonner A, Sando J. Examining the knowledge, attitude and use of research by nurses. J Nurs Manag. 2008;6(3):33443. [PMID: 18324993] doi:10.1111/j.1365-2834.2007.00808.x

29. McCleary L, Brown G. Use of the Edmonton Research Orientation Scale with nurses. J Nurs Meas. 2002;10(3):263-75. [PMID: 12885150]

30. Pain K, Magill-Evans J, Darrah J, Hagler P, Warren S. Effects of profession and facility type on research utilization by rehabilitation professionals. J Allied Health. 2004;33(1):3-9. [PMID: 15053214]

31. Henderson A, Winch S, Holzhauser K, De Vries S. The motivation of health professionals to explore research evidence in their practice: an intervention study. J Clin Nurs. 2006;15(12):1559- 64. [PMID: 17118078] doi:10.1111/j.13652702.2006.01637.x

32. Carlson CL, Plonczynski DJ. Has the BARRIERS Scale changed nursing practice? An integrative review. J Adv Nurs. 2008;63(4):322-33. [PMID: 18727758] doi:10.1111/j.1365-2648.2008.04705.x

33. Thomas A, Saroyan A, Dauphinee WD. Evidence-based practice: A review of theoretical assumptions and effectiveness of teaching and assessment interventions in health professions. Adv Health Sci Educ Theory Pract. 2011;16(2):253-76. [PMID: 20922477] doi: 10.1007/s10459- 010-9251-6

34. Kuh GD, Schneider CG. High-Impact Educational Practices: What they are, Who has Access to them, and Why they Matter. Washington DC: Association of American Colleges and Universities; 2008.

35. National Survey of Student Engagement. Engagement Indicators \& High-Impact Practices; 2015. Available at: http://nsse.indiana.edu/pdf/Els_and_HIPs_2015.pdf. Accessed: December 18, 2017.

36. National Survey of Student Engagement. NSSE 2016 High-Impact Practices: U.S. Summary Percentages by Student Characteristics. Available at: http://nsse.indiana.edu/2016_institutional_report/pdf/HIPTables/HIP.pdf. Accessed: December 18, 2017.

37. Pain K, Hagler $\mathrm{P}$, Warren $\mathrm{S}$. Development of an instrument to evaluate the research orientation of clinical professionals. Can J Rehabil. 1996;9(2):93-100.

38. Peachey A, Baller S. Ideas and approaches for teaching undergraduate research methods in the Health Sciences. Int J Teach Learn High Educ. 2015;27(3): 434-42.

39. IBM SPSS Statistics for Windows, Version 24.0, 2016. Armonk, NY: IBM Corp. 